Marquette University

e-Publications@Marquette

5-1-2012

\title{
Generation of Molecular Complexity from Cyclooctatetraene Using Dienyliron and Olefin Metathesis Methodology
}

Mohamed F. El-Mansy

Marquette University

Anobick Sar

Marquette University

Subhabrata Chaudhury

Marquette University

Nathaniel J. Wallock

Marquette University

William A. Donaldson

Marquette University, william.donaldson@marquette.edu

Accepted version. Organic and Biomolecular Chemistry, Vol. 10 (May, 2012): 4844-4846. DOI: (C) 2012 Royal Society of Chemistry. Used with permission.

The spectral data used in the research of this article may be found here. 


\title{
Generation of molecular complexity from cyclooctatetraene using dienyliron and olefin metathesis methodology ${ }^{\dagger}$
}

\author{
Mohamed F. El-Mansy \\ Department of Chemistry, Marquette University \\ Milwaukee, WI \\ Anobick Sar \\ Department of Chemistry, Marquette University \\ Milwaukee, WI \\ Subhabrata Chaudhury \\ Department of Chemistry, Marquette University \\ Milwaukee, WI \\ Nathaniel J. Wallock \\ Department of Chemistry, Marquette University \\ Milwaukee, WI \\ William A. Donaldson \\ Department of Chemistry, Marquette University \\ Milwaukee, WI
}

Transformation of the simple hydrocarbon cyclooctatetraene into a variety of polycyclic skeletons was achieved by sequential coordination to iron, reaction with electrophiles followed by allylated nucleophiles, decomplexation and olefin metathesis. 
The ability to rapidly generate diverse molecular complexity is one of the foundations of diversity-oriented synthesis (DOS). ${ }^{1}$ Within the general build/couple/pair (B/C/P) or functional group pairing strategy described by Schreiber and Nielsen ${ }^{2 \mathrm{a}}$ and Porco et $\mathrm{al}^{2}{ }^{2 \mathrm{~b}}$ the introduction of folding pathways allows for the transformation of different substrates into different scaffolds using a common reagent, while branching pathways allow for the transformation of a single substrate into different scaffolds with different reagents. ${ }^{1 \mathrm{~b}, 2 \mathrm{c}}$ From the infancy of DOS, olefin metathesis has played a prominent role in folding pathways, more recently including domino sequences of ring closing and/or ring opening metatheses. ${ }^{3}$ The DOS approach has lead to the discovery of molecules exhibiting anti-MRSA activity, ${ }^{4 a, b}$ or in vitro cytotoxicity against A549 lung carcinoma. ${ }^{4 c}$ As part of our interest in the generation of molecular complexity from simple hydrocarbons, ${ }^{5}$ we herein report the preparation of a variety of carbocyclic and heterocyclic structures from cyclooctatetraene (COT) using (dienyl)iron and olefin metathesis methodology.

Tricarbonyl(cyclooctatetraene)iron 1, readily prepared from СOT, ${ }^{6}$ reacts with a variety of electrophiles to form (dienyl)iron cations 2-4 (Scheme 1). ${ }^{5 a, 7}$ Reaction of 2-4 with either the anion (5) derived from dimethyl allylmalonate, or the anion (6) derived from (allyl)tosylamine, followed by oxidative decomplexation ${ }^{8}$ gave the racemic polyenes 7-12 respectively. These transformations may be regarded as branching pathways in diversity oriented synthesis. The structural assignments for 7-12 are based on their NMR spectral data. ${ }^{9}$ In particular, signals at $\delta 6.0-6.2(1 \mathrm{H})$ and $5.8-5.9 \mathrm{ppm}(1 \mathrm{H})$ in the ${ }^{1} \mathrm{H}$ NMR spectra of $\mathbf{7}$ and $\mathbf{8}$ are characteristic of the olefinic protons $\mathrm{H}-6 / \mathrm{H}-7$ in the bicyclo[3.2.1] octa-3,5-diene skeleton; ${ }^{5 b}$ signals at $\delta$ 0.65-0.75 $(1 \mathrm{H}), 1.1-1.2(1 \mathrm{H}), 5.3-5.45(1 \mathrm{H}), 5.6(1 \mathrm{H})$ and $6.1 \mathrm{ppm}$ $(1 \mathrm{H})$ in the ${ }^{1} \mathrm{H}$ NMR spectra of $\mathbf{9}$ and $\mathbf{1 0}$ are characteristic of the $\mathrm{H}-8$ and $\mathrm{H}-8^{\prime}$ cyclopropane protons, and the olefinic protons $\mathrm{H}-4, \mathrm{H}-5$, and $\mathrm{H}-6$ respectively; ${ }^{5 a}$ while signals at $\delta 3.4-3.6(1 \mathrm{H}, \mathrm{br} \mathrm{m}), 6.1(1 \mathrm{H}, \mathrm{dd})$ and 6.3-6.4 ppm $(1 \mathrm{H}, \mathrm{d})$ in the ${ }^{1} \mathrm{H}$ NMR spectra of $\mathbf{1 1}$ and $\mathbf{1 2}$ are characteristic of $\mathrm{H}-6, \mathrm{H}-8$, and $\mathrm{H}-9$ of a styryl-substituted cycloheptadiene. ${ }^{10}$ 

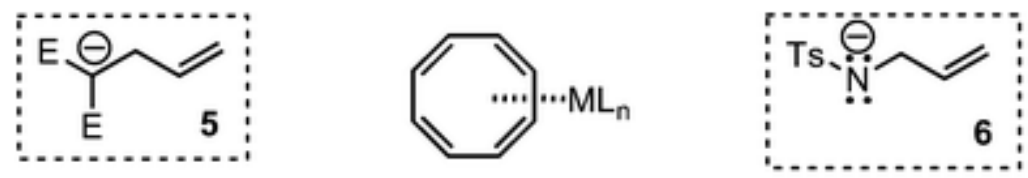

i) $\mathrm{PhCOCl}$

$\mathrm{AlCl}_{3}$

ii) $\mathrm{NH}_{4}{ }^{+} \mathrm{PF}_{6}{ }^{-}$<smiles>O=C(O)C1C2C=CC(CC2)C1C(=O)c1ccccc1</smiles>

$\mathrm{PF}_{6}{ }^{-}(\mathrm{CO})_{3}$

$\mathrm{ML}_{\mathrm{n}}=$ null

1, $\mathrm{ML}_{\mathrm{n}}=\mathrm{Fe}(\mathrm{CO})_{3}$

$\mathrm{Fe}(\mathrm{CO})_{5}, \mathrm{Me}_{3} \mathrm{NO}$

1) $\mathrm{PPh}_{3}, \mathrm{Me}_{3} \mathrm{NO}$

2) $\mathrm{HBF}_{4}$

1) $\left[\mathrm{C}_{7} \mathrm{H}_{7}\right]^{+} \mathrm{BF}_{4}^{-}$ pyridine

2) $\mathrm{HBF}_{4}$

2, (74\%, ref. $7 \mathrm{a})$

i) 5 or 6

ii) $[0 x]$
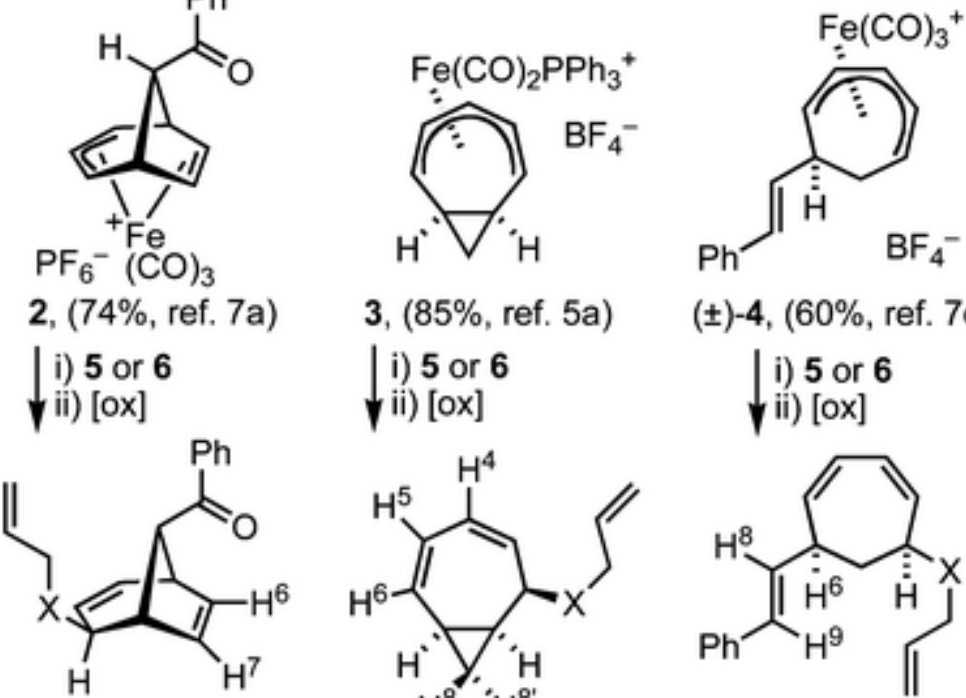

3 , $(85 \%$, ref. $5 a)$

$( \pm)-4,(60 \%$, ref. $7 d)$

i) 5 or 6

ii) [ox]

i) 5 or $\mathbf{6}$

ii) [ox]

$( \pm)-7, X=\mathrm{CE}_{2}$

(95\%)

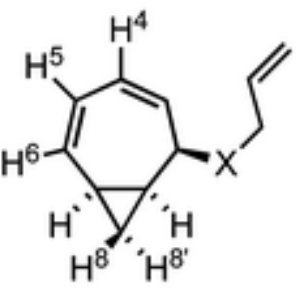<smiles>[Y]C1C=CC=CC(=C([2H])C([2H])c2ccccc2)C1</smiles>

or

$( \pm)-8, X=N T s$

(70\%)

$( \pm)-9, X=\mathrm{CE}_{2}$

(67\%)

or

$( \pm)-10, X=N T s$

$(58 \%)$
$( \pm)-11, X=C E_{2}$

$(64 \%)$

or

$( \pm)-12, X=N T s$

$(44 \%)$

Scheme $1\left(E=\mathrm{CO}_{2} \mathrm{Me}\right)$.

The presence of olefins in the free ligands 7-12 offers the possibility of ring rearrangement metathesis (RRM). ${ }^{11}$ Ring rearrangement metathesis occurs without the formation of a byproduct olefin, and as such these reactions may be considered an equilibrium between two isomeric structures. For this reason, substrates which undergo successful RRM reactions generally embody a degree of strain; this strain energy is released upon the rearrangement. To this end, reaction of $\mathbf{7}$ or $\mathbf{8}$ with Grubbs' 1st generation catalyst led exclusively to the RRM products 13 or 14 respectively (Scheme 2). Epimerization at C-10 of $\mathbf{1 3}$ or $\mathbf{1 4}$, under the reaction conditions or during spectroscopic characterization, was not

Organic and Biomolecular Chemistry, Vol. 10 (May 2012): pg. 4844-4846. DOI. This article is @ Royal Society of Chemistry and permission has been granted for this version to appear in e-Publications@Marquette. Royal Society of Chemistry does not grant permission for this article to be further copied/distributed or hosted elsewhere without the express permission from Royal Society of Chemistry. 
observed. The structural assignments for these products are based on their NMR spectral data. In particular, signals at $\delta 41.4,51.3$, and $62.1 \mathrm{ppm}$ in the ${ }^{13} \mathrm{C}$ NMR spectrum of $\mathbf{1 3}$ are characteristic of the $\mathrm{C}-2$, C-5, and C-1 carbons of a substituted dimethyl 3-cyclopentene-1,1dicarboxylate, ${ }^{12}$ while the signals at $\delta \sim 3.4 \mathrm{ppm}(\mathrm{t})$ in the ${ }^{1} \mathrm{H}$ NMR spectrum of $\mathbf{1 3}$ and $\mathbf{1 4}$ are characteristic of $\mathrm{H}-9 .{ }^{13}$

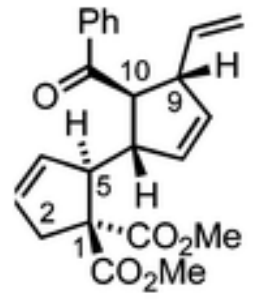

$( \pm)-13(62 \%)$

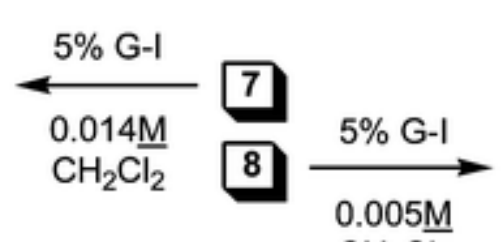

$\mathrm{CH}_{2} \mathrm{Cl}_{2}$

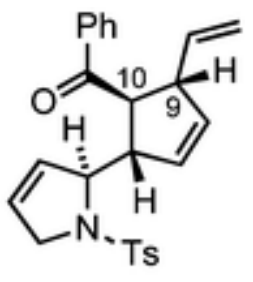

$( \pm)-14(80 \%)$

Scheme 2 ( $\left.\mathrm{G}-\mathrm{I}=\left(\mathrm{PCy}_{3}\right)_{2} \mathrm{Cl}_{2} \mathrm{Ru}=\mathrm{CHPh}\right)$.

Similarly, exposure of 9 to Grubbs' 1st generation catalyst gave the ring rearranged product 15 (Scheme 3 ). The presence of the substituted dimethyl 3-cyclopentene-1,1-dicarboxylate ring is evident by comparison to the ${ }^{13} \mathrm{C}$ NMR spectral data for 13. In addition, signals at $\delta 6.04(\mathrm{dt}, \mathrm{J}=0.9,10.9 \mathrm{~Hz}$ ) and 6.71 (dddd, $\mathrm{J}=0.9,10.2,11.3$, 16.7 Hz) are characteristic of $\mathrm{H}-2$ and $\mathrm{H}-3$ of a $1,3-Z$-butadien-5-yl sidechain. ${ }^{14}$ In contrast, reaction of $\mathbf{1 0}$ with Grubbs' 1 st or 2 nd generation catalyst gave only self-metathesis dimer 16, as an inseparable mixture of $d l$ - and meso-diastereomers. The structure of 16 was assigned on the basis of its NMR spectral data. In particular many of the signals in the ${ }^{1} \mathrm{H}$ NMR spectrum of $\mathbf{1 6}$ are remarkably similar to those of $\mathbf{8}$, the primary difference being the absence of signals corresponding to a mono-substituted olefin and the appearance of a narrow multiplet at $\delta 5.80-5.85(2 \mathrm{H})$ corresponding to the new 1,2-disubstituted double bond. In addition, the presence of a signal at $\delta 130.5 \mathrm{ppm}$ in the ${ }^{13} \mathrm{C}$ NMR spectrum of $\mathbf{1 6}$ (instead of a signal at ca. $\delta$ 117-119 ppm) indicated the presence of the self-metathesis olefin. 


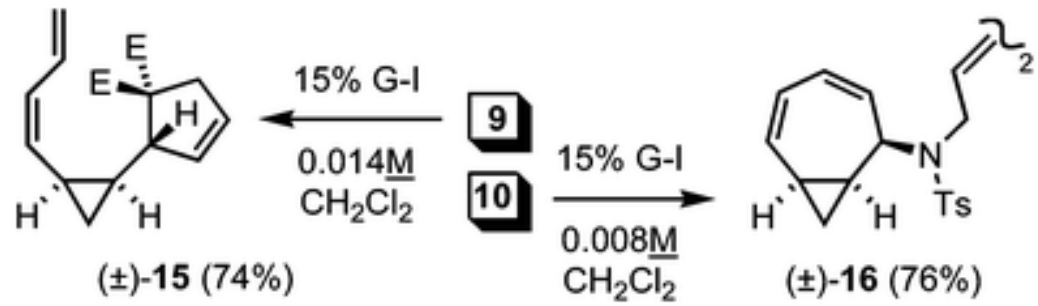

Scheme $3\left(\mathrm{E}=\mathrm{CO}_{2} \mathrm{Me} ; \mathrm{G}-\mathrm{I}=\left(\mathrm{PCy}_{3}\right)_{2} \mathrm{Cl}_{2} \mathrm{Ru}=\mathrm{CHPh}\right)$.

The difference in reactivity between $\mathbf{9}$ and $\mathbf{1 0}$ toward G-I catalyst may be rationalized on the basis of the allylmalonate group of $\mathbf{9}$ compared to the (allyl)tosylamine group of $\mathbf{1 0}$. Hoye and co-workers have previously noted that the allylmalonate group is particularly effective as an activator for initiating relay ring-closing metathesis (RRCM). ${ }^{15}$ These authors suggested that the rate-determining step in some RRCM reactions is the decomplexation of the product olefin (i.e. a cyclopentene ring), and that this decomplexation was more rapid for a cyclopentene ring with a sterically bulky dicarboxylate substitution pattern. In the present case initiation generates the Ru-carbene $\mathbf{A}$ (Scheme 4). Two pathways are available to this intermediate: either reversible intramolecular equilibration to afford intermediate $\mathbf{E}$, or irreversible self-metathesis dimerization. According to Hoye's proposal, the rate of decomplexation of $\mathbf{D}\left[\mathrm{X}=\mathrm{C}\left(\mathrm{CO}_{2} \mathrm{Me}\right)_{2}\right]$ is rapid (i.e. $k_{\text {off }}$ is fast), and thus $\mathbf{E}$ reacts with $\mathbf{9}$ to give the ring rearranged product $\mathbf{1 5}$ and regenerate intermediate $\mathbf{A}$. Conversely, intermediate $\mathbf{D}[X=N T s]$ undergoes decomplexation at a slower rate leading to the eventual irreversible self metathesis and concomitant formation of ethylene via the methylene carbene complex $\left[\left(\mathrm{Cy}_{3} \mathrm{P}\right) \mathrm{Cl}_{2} \mathrm{Ru}=\mathrm{CH}_{2}\right]$. 


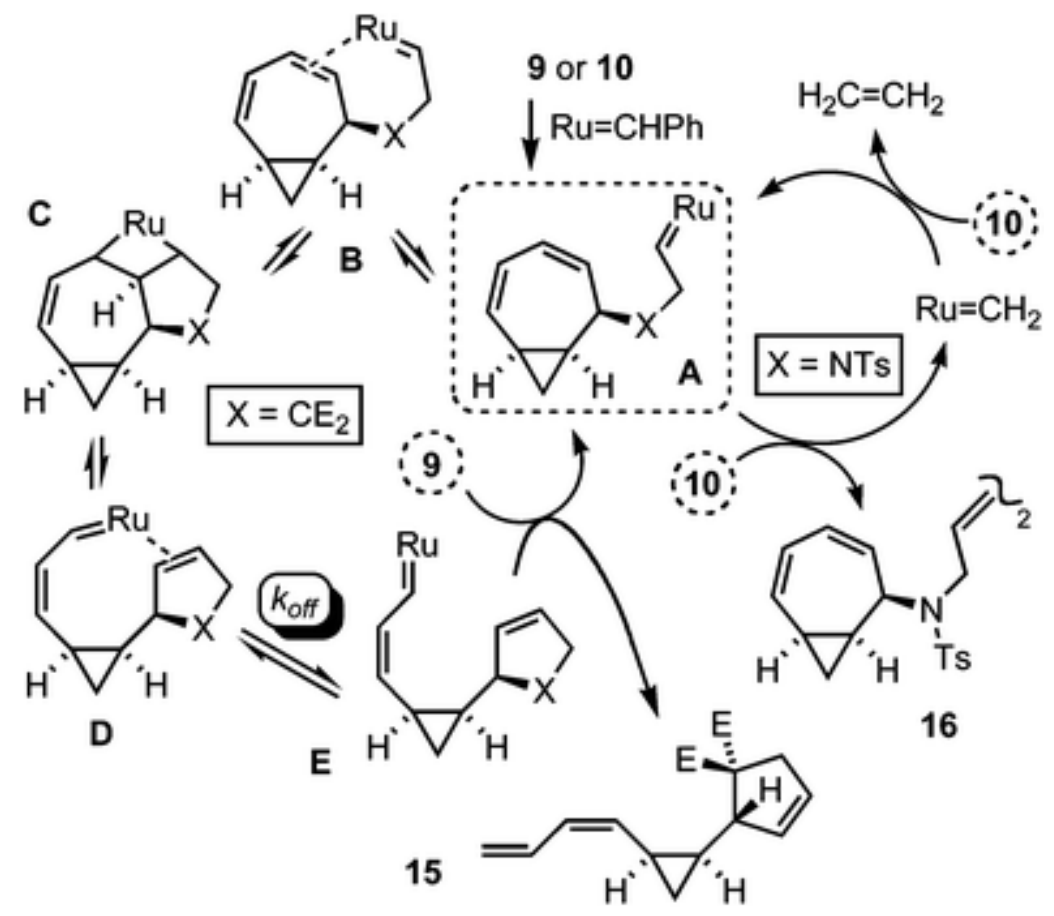

Scheme $\left.4\left(E=\mathrm{CO}_{2} \mathrm{Me} ; \mathrm{G}-\mathrm{I}=(\mathrm{PCy})_{3}\right)_{2} \mathrm{Cl}_{2} \mathrm{Ru}=\mathrm{CHPh}\right)$.

The substrates $\mathbf{1 1}$ or $\mathbf{1 2}$ contain a number of potential sites for olefin metathesis. In contrast to the reactions of 7-10, exposure of $\mathbf{1 1}$ to Grubbs' 1st generation catalyst led to the ring-closed product 17 (Scheme 5). The structural assignment for this product as the $\Delta^{6,7}$ isomer is based on its NMR spectral data. In particular, the ${ }^{1} \mathrm{H}$ NMR spectrum of 17 integrates to $18 \mathrm{Hs}$; five of which are olefinic. Furthermore, the ${ }^{13} \mathrm{C}$ NMR spectrum of 17 consisted of 15 signals with five olefinic methine carbons and one quaternary olefinic carbon. The reaction of 12 with Grubbs' 1st generation catalyst led to a complex mixture of products; use of Grubbs' 2nd generation catalyst gave the 2-azabicyclo[4.4.1] undeca-5,7,9-triene 18, which slowly underwent decomposition in solution. Olefin isomerization has previously been observed as a competitive side reaction of Ru-catalyzed olefin metathesis. ${ }^{16}$ Presumably the thermodynamically more stable $\Delta^{6,7}$ isomers $\mathbf{1 7 / 1 8}$ are formed by isomerization of the initially formed $\Delta^{7,8}$ isomer 19. 


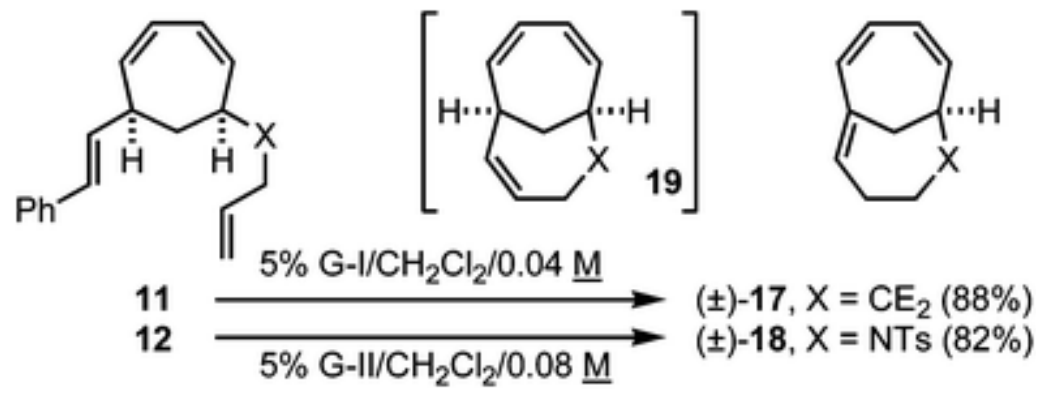

Scheme $5\left(E=\mathrm{CO}_{2} \mathrm{Me}_{2} ; \mathrm{G}-\mathrm{I}=(\mathrm{PCy})_{3}\right)_{2} \mathrm{Cl}_{2} \mathrm{Ru}=\mathrm{CHPh} ; \mathrm{G}-\mathrm{II}=$ $\left.\left(\mathrm{PC}_{3}\right)(\mathrm{IMes}) \mathrm{Cl}_{2} \mathrm{Ru}=\mathrm{CHPh}\right)$.

In summary, diverse molecular complexity may be generated in 5-6 steps by sequential reaction of (COT) $\mathrm{Fe}(\mathrm{CO})_{3}$ with an electrophile, followed by an allylated nucleophile and decomplexation (branching pathways), and olefin metathesis (folding pathway). The outcome of these reactions depends on the nature of the electrophile and nucleophile used. Applications of this methodology to target molecule synthesis will be reported in due course.

\section{Acknowledgements}

This work was supported by the National Science Foundation (CHE0415771 and CHE-0848870) and NSF instrumentation grants (CHE0521323). High-resolution mass spectra were obtained at the University of Nebraska-Center for Mass Spectrometry and the COSMIC lab at Old Dominion University.

\section{Notes and References}

1. (a) M. D. Burke, E. M. Berger and S. L. Schreiber, Science, 2003, 302, 613; (b) M. Dow, M. Fisher, T. James, F. Marchetti and A. Nelson, Org. Biomol. Chem., 2012, 10, 17.

2. (a) T. E. Nielsen and S. L. Schreiber, Angew. Chem., Int. Ed., 2008, 47, 48; (b) E. Comer, E. Rohan, L. Deng and J. A. Porco, Jr, Org. Lett., 2007, 9, 2123; (c) M. D. Burke and S. L. Schreiber, Angew. Chem., Int. Ed., 2004, 43, 46.

3. (a) R. J. Spandl, H. Rudyk and D. R. Spring, Chem. Commun., 2008, 3001; (b) D. Morton, S. Leach, C. Cordier, S. Warriner and A. Nelson, Angew. Chem., Int. Ed., 2009, 48, 104. 
4. (a) E. E. Wyatt, S. Fergus, W. R. J. D. Galloway, A. Bender, D. J. Fox, A. T. Plowright, A. S. Jessiman, M. Welch and D. R. Spring, Chem. Commun., 2006, 3296; (b) G. L. Thomas, R. J. Spandl, F. G. Glansdorp, M. Welch, A. Bender, J. Cockfield, J. A. Lindsay, C. Bryant, D. F. J. Brown, O. Loiseleur, H. Tudyk, M. Ladlow and D. R. Spring, Angew. Chem., Int. Ed., 2008, 47, 2828; (c) S. K. Ko, H. J. Jang, E. Kim and S. B. Park, Chem. Commun., 2006, 2962.

5. (a) N. J. Wallock and W. A. Donaldson, J. Org. Chem., 2004, 69, 2997; (b) S. Chaudhury, S. Lindeman and W. A. Donaldson, Tetrahedron Lett., $2007,48,7849$.

6. Y. Shvo and E. Hazum, J. Chem. Soc., Chem. Commun., 1975, 829.

7. (a) A. Davison, W. McFarlane, L. Pratt and G. Wilkinson, J. Chem. Soc., 1962, 4821; (b) M. Brookhart, E. R. Davis and D. L. Harris, J. Am. Chem. Soc., 1972, 94, 7853; (c) A. D. Charles, P. Diversi, B. F. G. Johnson and J. Lewis, J. Chem. Soc., Dalton Trans., 1981, 1906; (d) K. Broadley, N. G. Connelly, R. M. Mills, M. Whiteley and P. Woodward, J. Chem. Soc., Dalton Trans., 1984, 683.

8. Ceric ammonium nitrate [CAN] in methanol or acetonitrile was used as the standard oxidative decomplexation conditions. The formation of $\mathbf{1 0}$ required the use of DDQ as oxidant.

9. See ESI† for spectral data and copies of original spectra.

10. H. M. L. Davies, T. J. Clark and H. D. Smith, J. Org. Chem., 1991, 56, 3817.

11. O. Arjona, A. G. Csaky, M. C. Murica and J. Plumet, Tetrahedron Lett., 2000, 41, 9777; A. Ruckert, D. Reisel and S. Blechert, Tetrahedron Lett., 2001, 42, 5245; H. Hagiwara, T. Katsumi, S. Endou, T. Hoshi and T. Suzuki, Tetrahedron, 2002, 58, 6651; A. E. Nadany and J. E. Mckendrick, Synlett, 2007, 1663; H. Clavier, J. Broggi and S. P. Nolan, Eur. J. Org. Chem., 2010, 937.

12. (a) S. Sinha, T. Bhaumik and S. Ghosh, ARKIVOC, 2005, xi, 24; (b) K. L. Bray, G. C. Lloyd-Jones, M. Paza Munoz, P. A. Slatford, E. H. P. Tan, A. R. Tyler-Mahon and P. A. Worthington, Chem.-Eur. J., 2006, 12, 8650; (c) S. Schornshusen and J. Heck, Organometallics, 2007, 26, 5386. 
NOT THE PUBLISHED VERSION; this is the author's final, peer-reviewed manuscript. The published version may be accessed by following the link in the citation at the bottom of the page.

13. W. Boland and L. Jaenicke, J. Org. Chem., 1979, 44, 4819; L. A. Paquette, G. D. Crouse and A. K. Sharma, J. Am. Chem. Soc., 1982, $104,4411$.

14. S. P. Gunasekera, M. Gunasekera and R. E. Longley, J. Org. Chem., 1990, 55, 4912; W. A. Donaldson and L. Shang, Tetrahedron Lett., 1995, 36, 1575.

15. T. R. Hoye, J. Jeon and M. A. Tennakoon, Angew. Chem., Int. Ed., 2011, $50,2141$.

16. M. B. Dinger and J. C. Mol, Organometallics, 2003, 22, 1089; S. H. Hong, D. P. Sanders, C. W. Lee and R. H. Grubbs, J. Am. Chem. Soc., 2005, 127, 17160; F. C. Courchay, J. C. Sworen, I. Ghiviriga, K. A. Abboud and K. B. Wagener, Organometallics, 2006, 25, 6074.

\section{Footnote}

† Electronic supplementary information (ESI) available: Experimental procedures and copies of ${ }^{1} \mathrm{H}$ and ${ }^{13} \mathrm{C}$ NMR spectra of new compounds. See DOI: $10.1039 / c 20 b 25636 c$ 